\title{
Completely automated system for capacitance measurement through new accurate capacitance box
}

\author{
M. Helmy A. Raouf* \\ Department of Electrical Quantities Metrology, National Institute of Standards (NIS), Giza, Egypt
}

Received: 10 June 2017 / Accepted: 12 September 2017

\begin{abstract}
Capacitance boxes (CBs) are extensively used in electrical laboratories for calibration of capacitance measurement devices. In this paper, a new recently fabricated CB has been presented to be used for automatic calibrations through its 4096 output capacitance steps in the range from $100 \mathrm{nF}$ to $150 \mu \mathrm{F}$. Full specifications and characterization of this new $\mathrm{CB}$ have been investigated in detail including its frequency and voltage dependences. The presented $\mathrm{CB}$ has relative accuracy in the range from $\pm 5 \times 10^{-5}$ to $\pm 5 \times 10^{-4}$, whereas the relative uncertainty due to the combination effect is less than $15 \mathrm{ppm}$. The described $\mathrm{CB}$ has been used to construct fully automated capacitance measurement system at the National Institute of Standards (NIS), Egypt, using Andeen-Hagerling 2700A, opt. E \& opt. C, Ultra-precision Capacitance Bridge up to $1 \mu \mathrm{F}$. The second fully automated system for capacitance measurements is formed at NIS by An Agilent E4980A LCR meter, which is used to measure and characterize the higher capacitance values of the fabricated automated CB. Technical comparison between a previous $\mathrm{CB}$ and the new introduced one has been done to evaluate its performance.
\end{abstract}

Keywords: new capacitance box / automated measurement / capacitance measurement / decade capacitance / microcontroller technique

\section{Introduction}

Capacitance has many useful applications in various fields, and most of them require capacitance measurement that can be performed by different methods $[1,2]$. All of the instruments used for capacitance measurement should be calibrated by capacitance standards [3,4], which are continuously improved $[5,6]$. Capacitance decades are regular capacitance standards that are typically used for calibration of capacitance measuring devices manually. Such manual operation is difficult, confusing, and takes a long time. Traditionally, each decade capacitance is formed internally by 10 capacitive elements to generate 10 output capacitance steps values manually. It is practically known that any calibration becomes more convenient, easy, and accurate when using the automated devices. In [7] the same number of the output capacitance values, 10, is obtained only by using four internal capacitive elements. So, a capacitance box (CB) was fabricated using these two fourelement capacitance decades to provide a combination of 100 sequential capacitance steps, automatically, at the common output terminals of the two decades. Each one of these decades has four-capacitive elements having nominal

\footnotetext{
* Corresponding author: mohammed_makka@yahoo.com
}

values of $C_{1}=C, C_{2}=2 C, C_{3}=3 C$ and $C_{4}=4 C$, where $C$ is the nominal value of the capacitance per decade step [8]. To increase the output steps, decade capacitance of 15 output steps could be designed by using four internal capacitors. They have nominal capacitance values of $C_{1}=C, C_{2}=2$ $C, C_{3}=4 C$, and $C_{4}=8 C$, where $C$ is the nominal value of the capacitance per decade step [9].

Furthermore, three units of the decade capacitance of 15 output values are assembled to establish the recently fabricated CB to generate a huge number of the capacitance values, which are mainly used in fully automated calibration of the capacitance meters. The maximum number of the output capacitance steps produced by this CB is equal to 4096, whereas 1666 of them are different. These steps are considered as great increase compared to 1111 different output capacitance steps that can be obtained by the corresponding CB, but formed by the ordinary decades with 10 output steps [10].

This paper can be considered as an extended work, beyond [10], to give the full specifications and characterization of the recently fabricated automated CB. For this aim, two fully accurate automated capacitance measurement systems have been constructed at NIS by using AH2700A, opt. E \& opt. C, Ultra-precision Capacitance Bridge and Agilent E4980A LCR meter to cover the wide range of the CB. It is controlled manually, without 


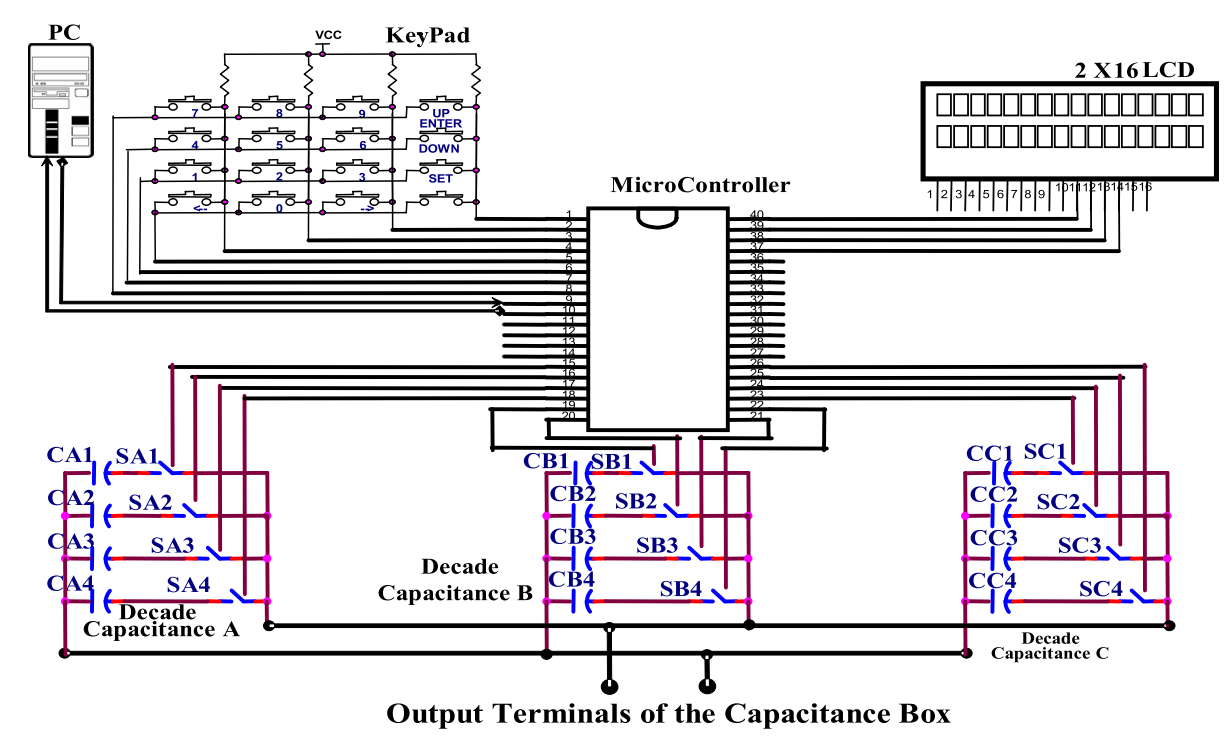

Fig. 1. Design of the fabricated capacitance box.

computer, using its keypad and manually or automatically using the computer by an especially designed LabVIEW program. Manual or automatic controls of the new CB could be achieved through 12 reed relays and only one microcontroller, which has been programmed by a prepared C-program. A general demonstrating flowchart is introduced to describe the whole automated measurement process including the fabricated $\mathrm{CB}$ and any capacitance measurement device.

\section{Design, fabrication, and control of the recent capacitance box}

Design and implementation of the new fabricated CB have been presented in brief. In addition, its methods of control are described in detail.

\subsection{Design of the new capacitance box}

Construction of the recently fabricated CB is essentially based on three capacitance decades, microcontroller circuit, keypad, and LCD as illustrated in Figure 1.

The first decade range is from $100 \mathrm{nF}$ to $1500 \mathrm{nF}$ by using capacitors with the values of $100 \mathrm{nF}, 200 \mathrm{nF}, 400 \mathrm{nF}$ and $800 \mathrm{nF}$, while the range of the second decade is from $1 \mu \mathrm{F}$ to $15 \mu \mathrm{F}$ by using $1 \mu \mathrm{F}, 2 \mu \mathrm{F}, 4 \mu \mathrm{F}$ and $8 \mu \mathrm{F}$ capacitors, and the third decade range is from $10 \mu \mathrm{F}$ to $150 \mu \mathrm{F}$ by using capacitors of $10 \mu \mathrm{F}, 20 \mu \mathrm{F}, 40 \mu \mathrm{F}$, and $80 \mu \mathrm{F}$ values. To connect or disconnect each one of these capacitive elements to the common output terminals of the box; corresponding reed relay, VR05R051A, is connected in series with each one of them as depicted in Figure 1. The fifteen output capacitance steps could be obtained from each decade separately and the remaining steps are generated by different possible combinations as the examples given in Table 1[10]. This controlling code is stored in the microcontroller ROM, ATMEGA8515-40- pin, through a prepared C-program to produce the required capacitance steps entered manually using the keypad or using the Lab VIEW program. Automatic control is obtained by a special LabVIEW program through a computer USB-to-serial converter.

\subsection{Practical fabrication of the new capacitance box}

The new fabricated CB shown in Figure 2; consists of two main units, which are control unit and standards unit, and they are connected together by data cable as illustrated in Figure 2a. The control unit shown in Figure $2 \mathrm{~b}$ has five printed circuit boards (PCBs); one for each decade including its four relays to control the corresponding four capacitors that are existed in the unit of the standards. The ATMEGA8515 microcontroller is fixed with its accessories on a fourth PCB and connected to the decades PCBs, and finally the fifth PCB is for the LCD. Circuits of the three decades are connected together to produce finally two common output terminals of the CB marked by red and green colors. At these terminals any required capacitance value entered by the keypad and shown by the LCD can be measured by a suitable capacitance measurement device.

The serial port is fixed on the microcontroller board to receive the orders form a computer through its USB port and therefore controlling the new fabricated CB automatically or manually as required.

\subsection{Manual/automatic control of the new capacitance box}

The programmed microcontroller generates the stored binary code to control the relays according to the required capacitance step manually or automatically. By using a computer, manual or automatic controls could be obtained through the specially designed LabVIEW program shown in Figure 3. Manual control, which means that "Selected Steps" option is used and any required 
Table 1. Combinations of the four capacitive elements of each decade to generate the required equivalent capacitance values with the corresponding relays states (S), where $\mathrm{S}=1$ (closed), $\mathrm{S}=0$ (open) and $\mathrm{A}, \mathrm{B}, \mathrm{C}$ are the entered required capacitance values for each decade respectively.

\begin{tabular}{|c|c|c|c|c|c|c|c|c|c|c|c|c|c|c|c|c|c|c|}
\hline \multicolumn{3}{|c|}{$\begin{array}{l}\text { Entered } \\
\text { value }\end{array}$} & \multicolumn{15}{|c|}{ Stored states of the relays } & \multirow{3}{*}{$\begin{array}{l}\text { Equivalent output } \\
\text { capacitance }(\mu \mathrm{F}) \\
\\
0.1 \times \text { Cout A } \\
+1 \times \text { Cout B } \\
+10 \times \text { Cout } \mathrm{C}\end{array}$} \\
\hline \multirow[t]{2}{*}{ A } & \multirow[t]{2}{*}{ B } & \multirow[t]{2}{*}{$\mathrm{C}$} & \multicolumn{5}{|c|}{$\begin{array}{c}\text { Decade } \\
\text { capacitance A } \\
\end{array}$} & \multicolumn{5}{|c|}{$\begin{array}{c}\text { Decade } \\
\text { capacitance B } \\
\end{array}$} & \multicolumn{5}{|c|}{$\begin{array}{c}\text { Decade } \\
\text { capacitance C } \\
\end{array}$} & \\
\hline & & & SA1 & SA2 & SA3 & SA4 & CoutA & SB1 & SB2 & SB3 & SB4 & CoutB & $\mathrm{SC} 1$ & $\mathrm{SC} 2$ & $\mathrm{SC} 3$ & $\mathrm{SC} 4$ & Cout $\mathrm{C}$ & \\
\hline 0 & 0 & 0 & 0 & 0 & 0 & 0 & 0 & 0 & 0 & 0 & 0 & 0 & 0 & 0 & 0 & 0 & 0 & 0 \\
\hline 1 & 0 & 0 & 1 & 0 & 0 & 0 & 1 & 0 & 0 & 0 & 0 & 0 & 0 & 0 & 0 & 0 & 0 & 0.1 \\
\hline 2 & 0 & 0 & 0 & 1 & 0 & 0 & 2 & 0 & 0 & 0 & 0 & 0 & 0 & 0 & 0 & 0 & 0 & 0.2 \\
\hline 10 & 3 & 8 & 0 & 1 & 0 & 1 & 10 & 1 & 1 & 0 & 0 & 3 & 0 & 0 & 0 & 1 & 8 & 84 \\
\hline 4 & 7 & 14 & 0 & 0 & 1 & 0 & 4 & 1 & 1 & 1 & 0 & 7 & 0 & 1 & 1 & 1 & 14 & 147.4 \\
\hline 13 & 15 & 15 & 1 & 0 & 1 & 1 & 13 & 1 & 1 & 1 & 1 & 15 & 1 & 1 & 1 & 1 & 15 & 166.3 \\
\hline 14 & 15 & 15 & 0 & 1 & 1 & 1 & 14 & 1 & 1 & 1 & 1 & 15 & 1 & 1 & 1 & 1 & 15 & 166.4 \\
\hline 15 & 15 & 15 & 1 & 1 & 1 & 1 & 15 & 1 & 1 & 1 & 1 & 15 & 1 & 1 & 1 & 1 & 15 & 166.5 \\
\hline
\end{tabular}

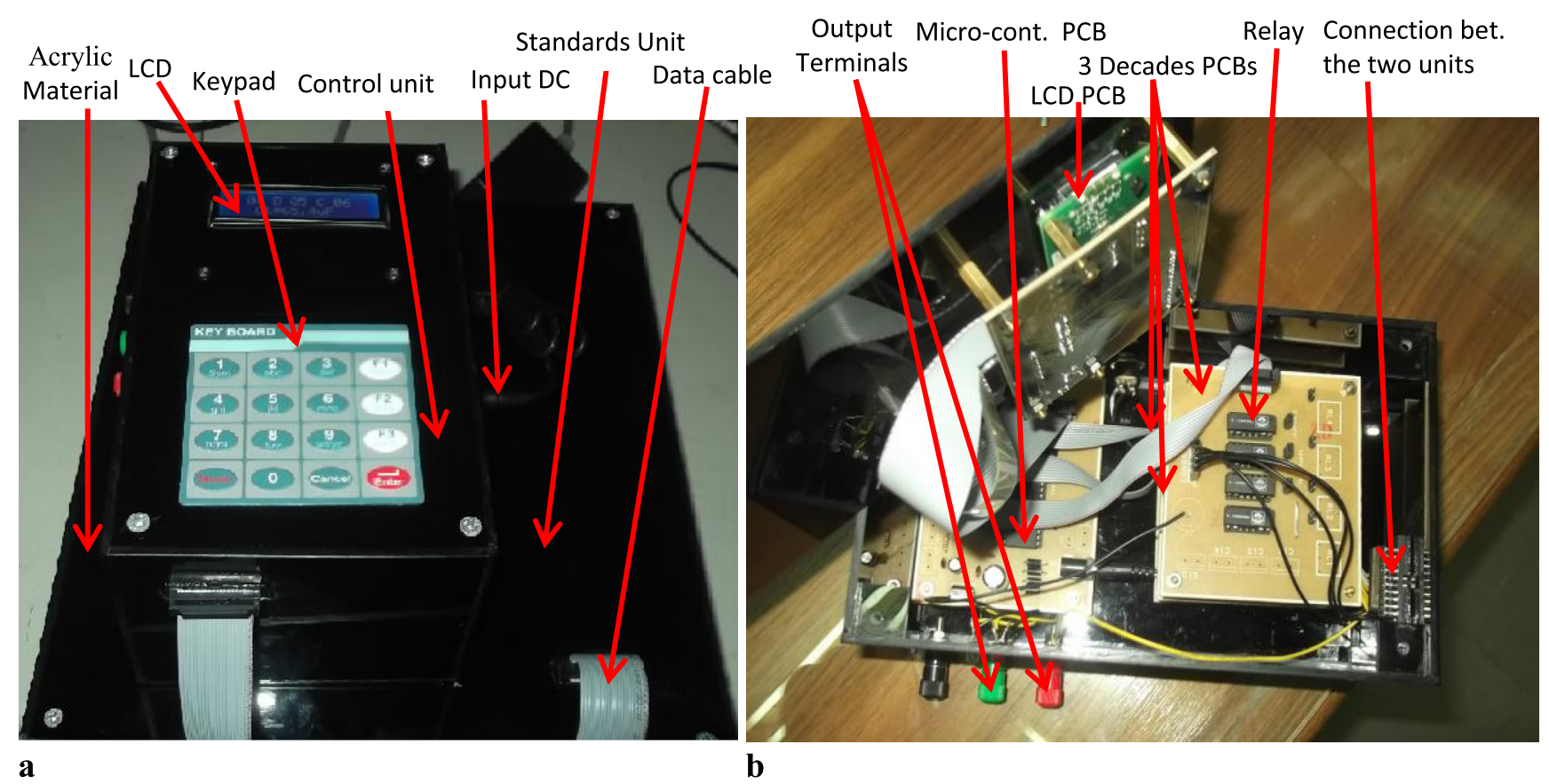

Fig. 2. Recently fabricated capacitance box. (a) Two units of the fabricated capacitance box. (b) Details of the control unit.

capacitance steps are produced by entering the corresponding combinations for $\mathrm{A}, \mathrm{B}$ and $\mathrm{C}$ decades, as for examples, demonstrated in the 19 steps shown in Figure 3. Then after pressing "RUN", the entered capacitance steps values are measured by any capacitance measurement device sequentially and after the adjusted intermediate delay time. The other option is "All Possible Steps", which means that the capacitance steps are automatically generated without entering the combinations A, B and $\mathrm{C}$ just by selecting the steps rang for each decade A, B, and C. Then by pressing "RUN", the steps of the whole selected ranges are generated sequentially. 


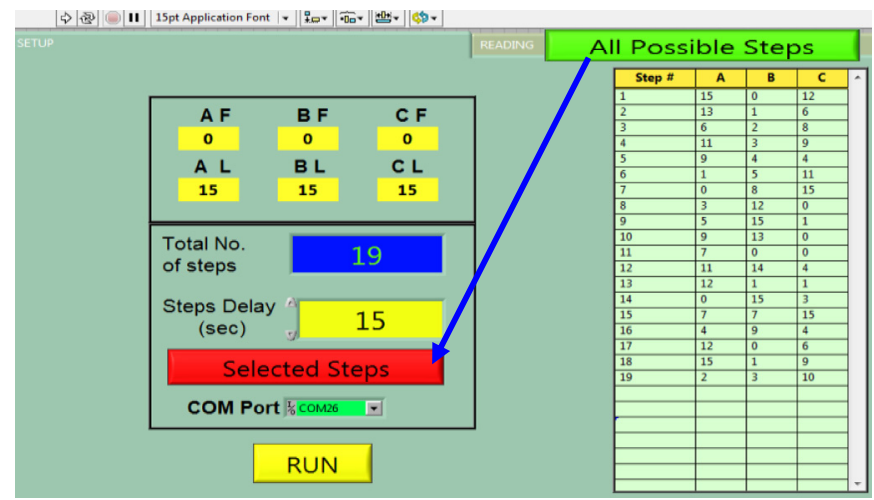

Fig. 3. Front panel of LabVIEW program that controls the capacitance box.

\section{Fully automated system for accurate measurement of capacitance}

Figure 4 demonstrates a flow chart, which presents the whole automatic calibration procedure. This full automatic closed loop system enables measurements of huge number of the capacitance steps accurately, easily, and quickly.

Fully automated systems for accurate capacitance measurements have been constructed at NIS by using an Agilent E4980A LCR meter, which measures all of the CB output steps, and by using AH2700A capacitance bridge through the new fabricated CB. Accordingly, its serial port is connected to a computer USB port by USB-to-serial converter and one of the measurement devices is connected to the same computer by a USB cable.

\section{Characterization and validation of the recently fabricated capacitance box}

Characterization of the new fabricated $\mathrm{CB}$ has been performed using the two described measurement systems, and then its full specifications are introduced. A technical comparison between the previously used $\mathrm{CB}$ and the introduced $\mathrm{CB}$ is presented for its validation.

\subsection{Measurements performed by Agilent E4980A LCR meter}

Using an Agilent E4980A LCR meter some measurements have been carried out and many parameters have been determined to evaluate the performance of the introduced CB. The fifteen output capacitance steps values of each decade have been measured separately and the relative deviation for each capacitance step from its nominal value has been computed according to the following simple equation:

\section{Relative deviation}

$=($ Actual value - Nominal value $) /($ Nominal value $)$

Average values of these results are represented and plotted in Figure 5. Therefore, the relative deviation limits for this $\mathrm{CB}$ have been found in the rage from $\pm 5 \times 10^{-5}$ to $\pm 5 \times 10^{-4}$, which is very satisfactory level of accuracy.

The determined relative deviation limits have been obtained for separate steps and many others, but as previously mentioned; there are 1666 different capacitance steps can be produced whereas the maximum number of the possible output capacitance steps generated by all possible combinations is 4096 capacitance values. So, there are about 2430 repeated output values, for example, the $1 \mu \mathrm{F}$ can be obtained by using two different combinations as indicated in Table 2 .

Consequently, there is a significant property that should be investigated for any CB, which is the effect of combination. It can be evaluated by comparing measured capacitance steps values generated by different combinations, but for the same nominal value. For example as

Fig. 4. Flow chart of the completely automated system for capacitance measurements. 


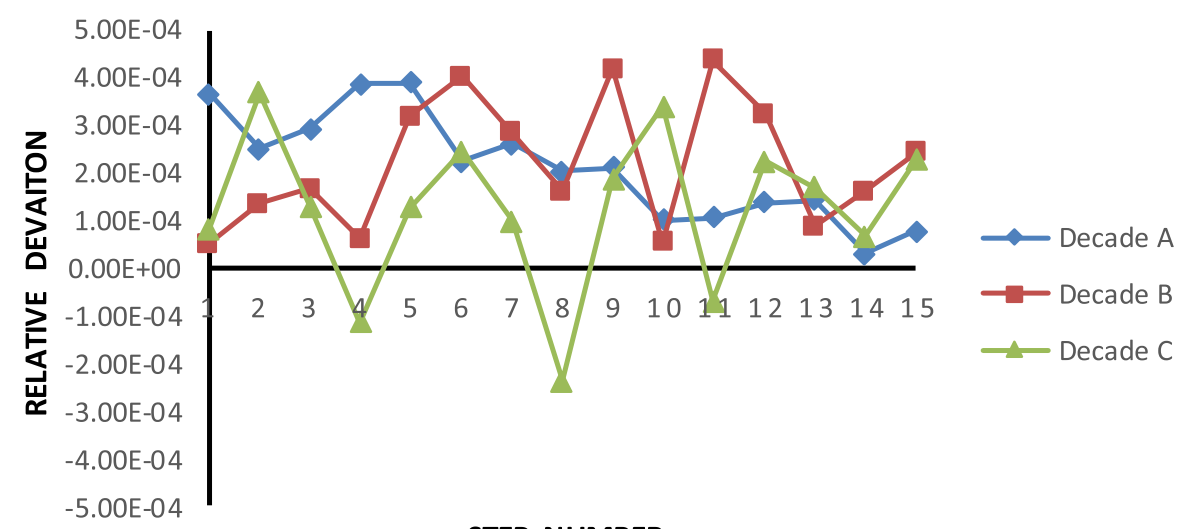

STEP NUMBER

Fig. 5. Relative deviation of the output capacitance steps.

Table 2. Different possible combinations to generate $1 \mu \mathrm{F}$.

\begin{tabular}{lllll}
\hline $\begin{array}{l}\text { Required } \\
\text { capacitance value }\end{array}$ & $\begin{array}{l}\text { Setting of decade A } \\
(100 \mathrm{nF} / \mathrm{step})\end{array}$ & $\begin{array}{l}\text { Step of decade B } \\
(1 \mu \mathrm{F} / \mathrm{step})\end{array}$ & $\begin{array}{l}\text { Step of decade } \mathrm{C} \\
(10 \mu \mathrm{F} / \mathrm{step})\end{array}$ & $\begin{array}{l}\text { Measured value } \\
(\mu \mathrm{F})\end{array}$ \\
\hline $1 \mu \mathrm{F}$ & 10 & 0 & 0 & 1.00008 \\
$1 \mu \mathrm{F}$ & 0 & 1 & 0 & 1.00006 \\
\hline
\end{tabular}

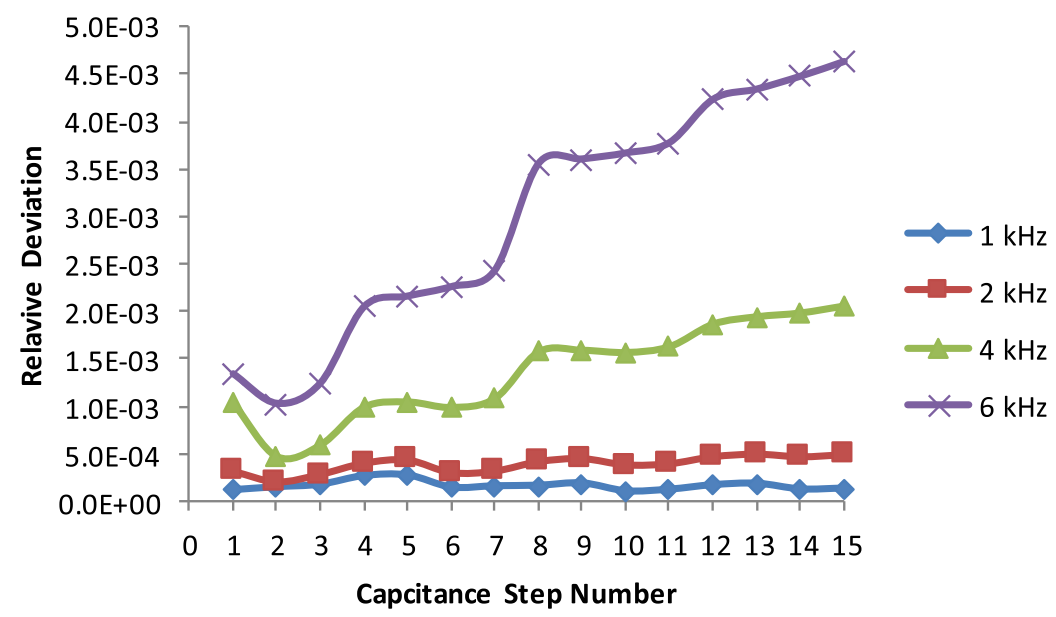

Fig. 6. Relative deviation of output capacitance steps at different frequencies and $1 \mathrm{~V}$.

clearly presented in Table 2 , the nominal capacitance value of $1 \mu \mathrm{F}$ could be generated by different two combinations to be measured at the CB output terminals. So, in this case, the combination effect can be determined by the comparison of these two practically measured values. Many other different cases have been investigated and all of the measured results have been carefully studied and analyzed to estimate the maximum relative difference, which is less than $\pm 25 \mathrm{ppm}$. By considering a rectangular distribution, the relative uncertainty because of the combination effect is less than $\pm 15 \mathrm{ppm}$.

Figure 6 presents frequency response of the new fabricated $\mathrm{CB}$ at $1 \mathrm{~V}$. It is proved that the new $\mathrm{CB}$ should be used at frequencies below $10 \mathrm{kHz}$; otherwise the accuracy will be less than $5 \times 10^{-3}$. Stability of the new fabricated CB has been studied for one year from $1 / 4 / 2015$ until $22 / 4 / 2016$ and it is in the range from 80 to $120 \mathrm{ppm} /$ year, depending on the capacitance value. Repeatability of the measured capacitance values has been analyzed, and it is in the order of $1 \mathrm{ppm}$.

\subsection{Measurements performed by ultra-precision capacitance bridge}

Andeen-Hagerling 2700A, opt. E \& opt. C, ultra-precision capacitance bridge has been used to study the voltage dependence instead of the Agilent E4980A LCR meter because it has limited testing voltage, which is only $2 \mathrm{~V}$. The maximum measurement range of the used capacitance bridge is $1.5 \mu \mathrm{F}$ with a maximum testing voltage of 15 , 


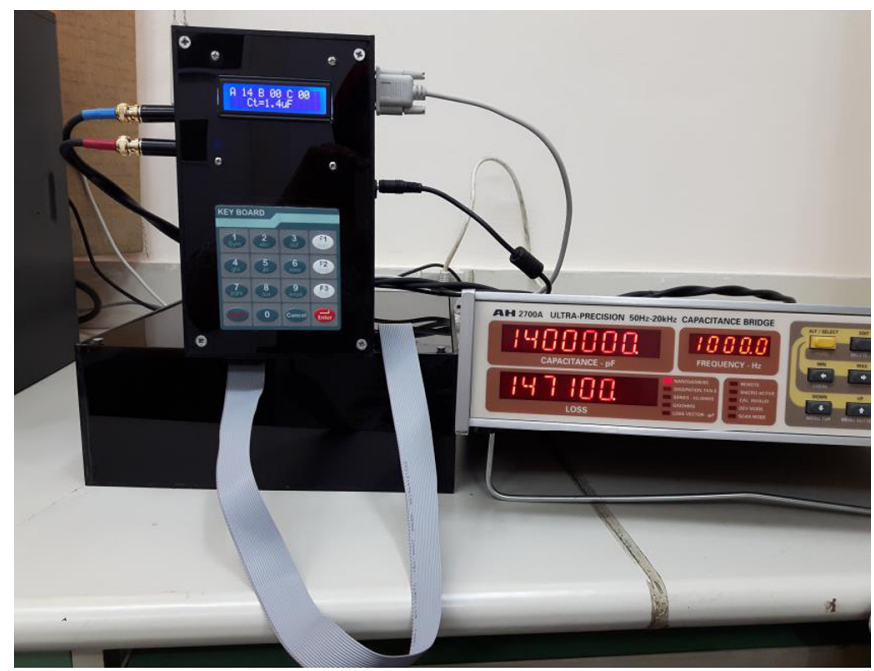

Fig. 7. Automated capacitance measurements using ultra-precision capacitance bridge.

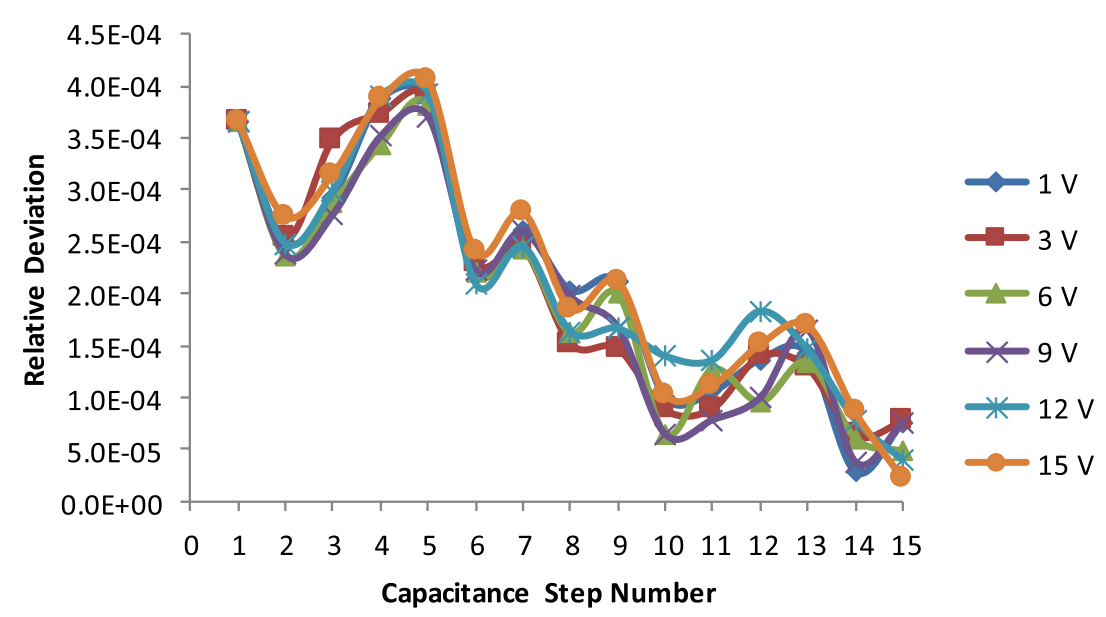

Fig. 8. Relative deviation of the output capacitance steps at different voltages and $1 \mathrm{kHz}$.

therefore the first decade steps of the new CB have been only measured at different voltages and at $1 \mathrm{kHz}$ frequency as, for example, demonstrated in Figure 7.

As cleared in Figure 8, at different voltage levels, the curves of the relative deviation of the output capacitance steps are consistent and the values of the capacitance steps are relatively stable. This means that the voltage dependence of the verified $\mathrm{CB}$ is relatively small due to its improved performance. Accordingly, by analyzing the obtained results the relative voltage dependence is found to be less than $\pm 1 \times 10^{-6} / \mathrm{V}$.

\subsection{Specifications and advantages of the new capacitance box}

The metrology society should know the properties of the new fabricated $\mathrm{CB}$, as a new capacitance standard, so its main specifications are presented in Table 3.
These characteristics improve the performance of the new fabricated CB especially when it is used in many important applications such as full automatic calibration of capacitance measurement devices and testing their linearity.

\subsection{Comparison between the previous $C B$ and the recently fabricated $C B$}

A technical comparison between the previous $\mathrm{CB}$ [8], and the recently fabricated $\mathrm{CB}$ is carried out to validate its performance. As presented in Table 4, this comparison is made for their main specifications.

It is proved form the above elementary comparison that the new fabricated CB has better electrical performance than the previously used CB. Both of them can be used for automatic calibration of the capacitance measurement devices, but the recently fabricated CB is better because of its huge number of the output capacitance steps. In 
Table 3. Main specifications of the new fabricated capacitance box.

\begin{tabular}{ll}
\hline Item & Value $/$ description \\
\hline Operating power & $12 \mathrm{VDC}$ \\
Operating frequency range & $<10 \mathrm{kHz}$ \\
Maximum measuring voltage & $75 \mathrm{VAC}$ (peak) \\
Number of decades/box & 3 decades \\
Number of capacitive elements/decade & 4 capacitors instead of 10 in the old decades \\
Nominal values of the used standard capacitors & $100 \mathrm{nF}, 200 \mathrm{nF}, 400 \mathrm{nF}, 800 \mathrm{nF}, 1 \mu \mathrm{F}, 2 \mu \mathrm{F}, 4 \mu \mathrm{F}, 8 \mu \mathrm{F}$, \\
& $10 \mu \mathrm{F}, 20 \mu \mathrm{F}, 40 \mu \mathrm{F}$, and $80 \mu \mathrm{F}$ \\
Type of the used capacitive components & Silvered mica for $(100 \mathrm{nF}$ to $1 \mu \mathrm{F}$ ) and metallized \\
& polypropylene sulfide for $>1 \mu \mathrm{F}$ \\
Number of capacitance steps/decade & $15 \mathrm{instead}$ of 10 in the old decades \\
Capacitance steps of each decade & $100 \mathrm{nF}$ for the first decade, $1 \mu \mathrm{F}$ for the second decade, \\
& and $10 \mu \mathrm{F}$ for the third decade \\
Whole output capacitance range & $100 \mathrm{nF}$ to $150 \mu \mathrm{F}$ \\
Maximum setting value & $166.5 \mu \mathrm{F}$ \\
Maximum possible output capacitance steps & $4096 \mathrm{instead}$ of 1331 in the old corresponding box \\
Maximum different output capacitance steps & $1666 \mathrm{instead}$ of 1111 in the old corresponding box \\
Operating temperature and humidity & $10^{\circ} \mathrm{C}$ to $40^{\circ} \mathrm{C} ;<80 \%$ RH \\
Storage temperature & $-20{ }^{\circ} \mathrm{C}$ to $65^{\circ} \mathrm{C}$ \\
Basic test conditions & $1 \mathrm{kHz}, 1 \mathrm{~V}$ rms, $23^{\circ} \mathrm{C}$ \\
Temperature coefficient & 10 to 25 ppm $/{ }^{\circ} \mathrm{C}$, depending on the capacitance value \\
Dissipation factor & $85-400 \mathrm{ppm}$ depending on the capacitance value \\
Relative deviation of the output capacitance steps & $\pm 5 \times 10^{-5}$ to $\pm 5 \times 10^{-4}$ \\
Estimated stability over one year & $80-120 \mathrm{ppm} /$ year, depending on the capacitance value \\
Relative voltage dependence & $\pm 1 \times 10^{-6} / \mathrm{V}$ \\
Measurements repeatability & In the order of $1 \mathrm{ppm}$, depending on the \\
Relative uncertainty due to the combination effect & measured capacitance value \\
Box size & $<15 \mathrm{ppm}$, on the average \\
Mass & $20.5 \mathrm{~cm} \times 12.5 \mathrm{~cm} \times 10.5 \mathrm{~cm}$ for control unit and \\
\hline & $32.5 \mathrm{~cm} \times 27.5 \mathrm{~cm} \times 10.5 \mathrm{~cm}$ for the unit of the standards \\
& $<4.7 \mathrm{~kg}$ \\
\hline
\end{tabular}

Table 4. Comparison between the previous $\mathrm{CB}$ and the new CB.

\begin{tabular}{lll}
\hline Item & Previous CB & New fabricated CB \\
\hline $\begin{array}{l}\text { No. of decades/box } \\
\text { No. of microcontrollers/box }\end{array}$ & 2 & 3 \\
Type of the used capacitive components & One microcontroller/decade & $\begin{array}{l}\text { Only one for the whole box } \\
\text { Silvered mica and metallized } \\
\text { polypropylene sulfide }\end{array}$ \\
No. of capacitive elements/decade & 4 & 4 \\
Nominal capacitance values & $C, 2 C, 3 C$ and $4 C$ & $C, 2 C, 4 C$ and $8 C$ \\
No. of capacitance steps/decade & 10 & 15 \\
Range & $100 \mathrm{nF}$ to $10 \mu \mathrm{F}$ & $100 \mathrm{nF}$ to $150 \mu \mathrm{F}$ \\
Maximum setting value & $11 \mu \mathrm{F}$ & $166.5 \mu \mathrm{F}$ \\
Maximum different output capacitance steps & 100 & 1666 \\
Relative deviation of the output steps & $\pm 2 \times 10^{-4}$ to $\pm 2 \times 10^{-3}$ & $\pm 5 \times 10^{-5}$ to $\pm 5 \times 10^{-4}$ \\
Measurements repeatability & $\mathrm{About} 27 \mathrm{ppm}$ & $\mathrm{About} 1 \mathrm{ppm}$ \\
Maximum measuring voltage & $50 \mathrm{VAC}$ & $75 \mathrm{VAC}$ \\
Temperature coefficient & $1000 \mathrm{ppm} /{ }^{\circ} \mathrm{C}$ & $10-25 \mathrm{ppm} /{ }^{\circ} \mathrm{C}$ \\
Automatic calibrations & Can be used & Can be also used \\
\hline
\end{tabular}


addition, they have minimum cost due to the minimum number of the used capacitive elements per decade, which is four instead of 10 in the traditional manual old decades.

\section{Conclusion}

The introduced CB has been established by 12 capacitors connected to their corresponding 12 reed relays and controlled by only one microcontroller. Using all possible combinations; the maximum output capacitance steps are 4096, whereas 1666 of them are different from each other. Therefore, the new CB is very reliable during manual or automatic calibrations of the capacitance meters. Relative accuracy of the output capacitance steps is in the range between $\pm 5 \times 10^{-5}$ and $\pm 5 \times 10^{-4}$, while the relative uncertainty due to the combination effect is less than $15 \mathrm{ppm}$. Moreover, the relative voltage dependence is less than $\pm 1 \times 10^{-6} / \mathrm{V}$. By comparing the specifications of the previously available CBs with the new $\mathrm{CB}$; it has many advantages such as huge output steps, wider capacitance range, relatively high accuracy, and enhanced electrical properties. The new fabricated $\mathrm{CB}$ has been used to establish completely automated systems for accurate capacitance measurements, for the first time, at NIS. Capacitance range of the presented box can be simply extended to lower values by adding extra decades.

The author is grateful to the National Institute of Standards (NIS).

\section{References}

1. D.X. Dai, X.B. He, W. Wang, Y.Q. Li, Improvement of highvalue capacitance measurement, IEEE Trans. Instrum. Meas. 62, 1795-1800 (2013)

2. A. Zanobini, G. Iuculano, A. Falciani, Automatic-test equipment for the characterization of aluminum electrolytic capacitors, IEEE Trans. Instrum. Meas. 55, 682-688 (2006)

3. R.D. Lee, H.J. Kim, Y.P. Semenov, Quasi-monolithic toroidal cross-capacitor, IEEE Trans. Instrum. Meas. 54, 538-541 (2005)

4. L. Callegaro, V. D'Elia, D. Serazio, 10-nF capacitance transfer standard, IEEE Trans. Instrum. Meas. 54, 1869-1872 (2005)

5. S.S. Moodley, W. van den Berg, C.S. Veldman, Improving the mechanical stability of a standard capacitor, IEEE Trans. Instrum. Meas. 52, 392-395 (2003)

6. F. Castelli, A proposal for a toroidal cross-capacitor, IEEE Trans. Instrum. Meas. 49, 721-726 (2000)

7. M. Helmy A. Raouf, Decade Capacitance Formed by Minimum Number of Elements, Ministry of Higher Education and Scientific Research, Patent Office, Cert. No. 24446, 2009

8. M. Helmy A. Raouf, Manual/automated capacitance box using micro-controller technique, MAPAN 26, 105-113 (2011)

9. M. Helmy A. Raouf, Automated Decade Capacitance of Fifteen Output Values, Ministry of Higher Education and Scientific Research, Patent Office, Cert. No. 26040, 2012

10. M. Helmy A. Raouf, Fully automated capacitance measurement system using new precise capacitance box, in IEEE Conference on Precision Electromagnetic Measurements (CPEM 2016 Digest), Ottawa, Canada, 10-15 July 2016 (2016), pp. 390-391, doi:10.1109/CPEM.2016.7540612.

Cite this article as: M. Helmy A. Raouf, Completely automated system for capacitance measurement through new accurate capacitance box, Int. J. Metrol. Qual. Eng. 8, 22 (2017) 